\title{
Determination of left ventricular volumes by Simpson's rule in infants and children with congenital heart disease
}

\author{
TOSHIHIRO INO,* LEE N BENSON, HAVERJ MIKALIAN, ROBERT M FREEDOM \\ RICHARD D ROWE $\dagger$ \\ From the Department of Pediatrics, Division of Cardiology and the Variety Club Cardiac Catheterization \\ Laboratories, Hosital for Sick Children, Toronto, Ontario, Canada
}

SUMMARY Regression equations were developed from left ventricular casts of known volumes tథ calculate left ventricular volumes from biplane cineangiography obtained in non-standard views Volumes were calculated by Simpson's rule from casts of postmortem specimens from patient with congenital heart disease. The casts were divided into two groups: those that came front patients with abnormal right ventricular haemodynamic function (group $1, n=11$ ) and those tha를 came from patients in which it was normal (group $2, n=9$ ). Biplane cinegrams were taken in conventional (anteroposterior/lateral, right anterior oblique/left anterior oblique) and non $\infty$ conventional (long axis oblique, hepatoclavicular, and sitting up) projections. The true volume of each cast was determined from its weight and specific gravity. Correlations between measured and true volumes $(r=0.96$ to 0.99 ) were excellent in all projections, although each projections overestimated the true volumes (slope $=0.72$ to 0.94 ). The regression equations obtained frond conventional views were significantly different from those from the non-conventional views however, the regression slopes in group 1 were not different from those in group 2 in any view. $\vec{\nexists}$

Regression equations obtained by Simpson's rule do not seem to be affected by the haemodynamic state of the right ventricle. Different regression equations are required to measure left ventricular volumes from non-conventional angiograms.

In angiographic measurement of the left ventricle the area-length method described by Dodge and colleagues has become popular. ${ }^{1}$ This method was derived from the assumption that the left ventricular cavity could be represented as a three-dimensional ellipsoid of revolution. In complex congenital heart disease, however, the left ventricle is not usually elliptical and it is affected by right ventricular haemodynamic function. Data from our laboratory question whether the area-length method can be applied to the non-elliptical left ventricle. ${ }^{2}$

Simpson's rule seemed to be independent of the

Requests for reprints to Dr Lee N Benson, Hospital for Sick Children, Room 4515, 555 University Avenue, Toronto, Ontario, Canada M5G 1 X8.

^Present address: Department of Paediatrics, Juntendo University School of Medicine, 2-1-1 Hongo, Bunkyo-ku, Tokyo, 113, Japan.

†Dr Rowe died on 18 January 1988.

Accepted for publication 8 September 1988 shape of the ventricle when it was applied to determining the volume of irregularly shaped rigif ventricles. ${ }^{3}$ We have assessed the accuracy of apply ing Simpson's rule to the determination of the volume of the left ventricle in patients with congenital heart disease and have evaluated the results of measuring left ventricular volume from convention (anteroposterior/lateral, standard $30^{\circ} / 60^{\circ}$ right and. left anterior oblique) and non-conventional (lon axis oblique, hepatoclavicular, and sitting ups projections.

\section{Patients and methods}

We studied casts of the left ventricles of 20 hearts children and infants who died of congenital heart disease. All clinical data and data on haemodynamic function were reviewed. There were four hearts with endocardial fibroelastosis; three with atrial septif defect; three with tetralogy of Fallot; two with complete transposition of great arteries with intaet 
ventricular septum; two with coarctation of aorta; two with total anomalous pulmonary venous return; two with myocardial disease; one with ventricular septal defect; and one with congenital mitral stenosis with pulmonary hypertension. The casts were prepared as previously described. ${ }^{4}$ Briefly, the postmortem specimens selected were fixed in formalin; those in which ventricular shape had obviously been shrunk by fixation were excluded. After the removal of blood clots from both ventricles, the mitral and tricuspid valves were oversewn and the walls were glued with a cyanoacrylate compound (910 Adhesive, Permabond International Division). A silicon rubber material (3110 RTV, Dow Corning) mixed with barium sulphate powder (EZEM Co) was injected simultaneously into both ventricles through the aortic and pulmonary valves. The injection into the ventricles was performed as slowly as possible and without exerting positive pressure so as to avoid displacing the ventricular septum. After the casts had hardened, the left and right ventricular walls and free walls were incised and the casts were carefully removed. The true volumes of left ventricular casts were determined by weight divided by the specific gravity of the silicon rubber $(1 \cdot 17 \mathrm{~g} / \mathrm{dl})$.

Casts were placed on a goniometer designed in our laboratory and positioned on the catheterisation table. The vertical and horizontal image intensifiers were fixed in anteroposterior and lateral positions respectively. The initial reference position for the cast was established by a line connecting the apex with the most distal part of mitral valve that formed a $35^{\circ}$ angle with the vertical plane and a $35^{\circ}$ angle with the horizontal plane. The casts were filmed in conventional (anteroposterior/lateral, standard right anterior oblique and left anterior oblique) and nonconventional (long axis oblique, hepatoclavicular, and sitting up) positions. The exact positions of long axis oblique, hepatoclavicular, and sitting up projections were determined as previously described. ${ }^{5}$ The films were projected on a screen and the images were traced on to paper. After each film a grid of $1 \mathrm{~cm}$ squares was filmed at the cast centre parallel to each image intensifier.

The volumes of the left ventricular casts were calculated by Simpson's rule, which assumes that the cross section of each slice is cylindrical and that the total volume is the sum of all cylinders. ${ }^{6}$ For this calculation we used an IBM PC computer with dedicated software supporting a graphics tablet (Trinity Computer Systems, Houston, Texas).

We used standard linear regression analysis to compare the calculated volumes with the true volumes. We investigated the influence of left ventricular shape on volume determination by dividing the casts into those from patients with abnormal right ventricular haemodynamic function (group $1, \mathbf{n}=11$; atrial septal defect, tetralogy of Fallot, complete transposition of great arteries with intact ventricular septum, total anomalous pulmonary venous return, and congenital mitral stenosis with pulmonary hypertension) and those with normal right ventricular haemodynamic function (group 2, $n=9$; endocardial fibroelastosis, ventricular septal defect, coarctation of aorta, and myocardial disease). We used analysis of covariance for between group comparisons of regression equations obtained from the five projections.

\section{Results}

The true volumes of the left ventricular casts ranged from 1 to $49 \mathrm{ml}$ (mean (SD) $14(13) \mathrm{ml}$ ) and those of the right ventricular casts from 2 to $34 \mathrm{ml}$ (16 (10) $\mathrm{ml})$. The ratio of the true volumes of the left and right ventricles was larger in group 2 than in group 1 (1.4 $(0.6) v 0.7(0.4), \mathrm{p}<0.01)$. These preliminary results suggested that the two groups could be separated on the basis of the haemodynamic function of the right ventricle. The shape of the left ventricular casts

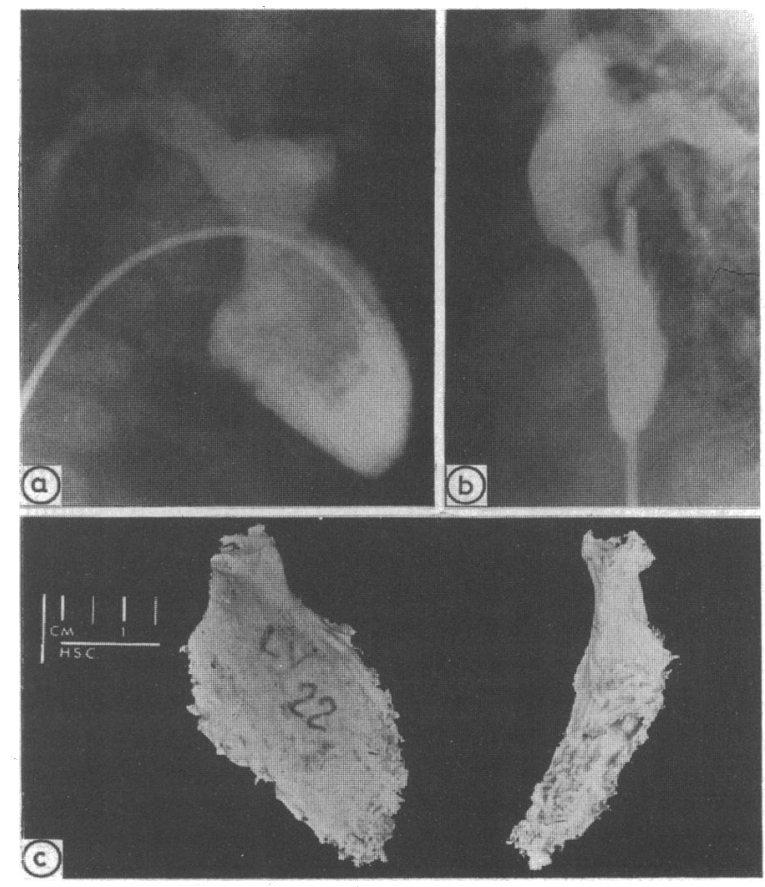

Figure The shape of the left ventricle shown by left ventriculography in one patient ( $a$ and $b$ ) and $(b)$ a cast from another patient. Left ventriculography was performed in a patient with complete transposition of great arteries with intact ventricular septum and the cast was made from a postmortem specimen from a patient with complete transposition of great arteries with intact ventricular septum. 
Table 1 Regression equations obtained from all 20 casts

\begin{tabular}{llll}
\hline Projection & $\begin{array}{l}\text { Regression } \\
\text { equation }\end{array}$ & r value & $\begin{array}{l}\text { Standard } \\
\text { error } \\
\text { of estimate }\end{array}$ \\
\hline $\begin{array}{l}\text { Anteroposterior/lateral } \\
\text { Right/left anterior }\end{array}$ & $\mathrm{y}=0.72 \mathrm{x}-1.5$ & 0.96 & 3.6 \\
oblique & $\mathrm{y}=0.79 \mathrm{x}+2.4$ & 0.98 & 2.6 \\
$\begin{array}{l}\text { Long axis oblique } \\
\text { Hepatoclavicular }\end{array}$ & $\mathrm{y}=0.84 \mathrm{x}-2.4$ & 0.98 & 2.6 \\
Sitting up & $\mathrm{y}=0.86 \mathrm{x}-1.0$ & 0.97 & 3.3 \\
\hline
\end{tabular}

$x$, calculated volume; $y$, true volume; $r$, correlation coefficient.

Anteroposterior lateral $v$ long axis oblique, hepatoclavicular, and sitting up projections, $\mathrm{p}<0.025$.

Right/left anterior oblique $v$ hepatoclavicular and sitting up projections, $\mathrm{p}<0.05$.

closely resembled that of the left ventricle seen on the ventriculograms in the same projections (figure). Table 1 shows the results of the volume calculation in all projections. Regression analysis obtained from the 20 casts yielded excellent correlation coefficients ranging from 0.96 to 0.99 with small standard errors of estimate $(2.1$ to $3.6 \mathrm{ml})$. There were no differences in the slopes of the regression equations between the anteroposterior/lateral and right/left anterior oblique, or among the non-conventional axial views by analysis of covariance (table 1). However, the regression equations between anteroposterior/lateral and the non-conventional views, and right/left anterior oblique and two of the axial views (hepatoclavicular and sitting up) were significantly different $(\mathrm{p}<0.05)$.

Comparison of the regression equations between group 1 and 2 showed no significant differences of slopes or intercepts in the five projections.

\section{Discussion}

Angiographic measurement of ventricular volume requires the use of regression equations to obtain corrected volumes. Regression equations have been obtained by comparing the known volumes of casts made from postmortem specimens and the volumes

Table 2 Comparison between groups 1 and 2 of regression equations

\begin{tabular}{llll}
\hline & $\begin{array}{l}\text { Regression } \\
\text { equation }\end{array}$ & r value & $\begin{array}{l}\text { Standard } \\
\text { error } \\
\text { of estimate }\end{array}$ \\
Projection & Anteroposterior/lateral (1) $y=0.54 x+0.4$ & 0.94 & 1.9 \\
(2) $y=0.72 x-0.9$ & 0.96 & 4.9 \\
Right/left anterior & (1) $y=0.70 x-1.7$ & 0.95 & 1.6 \\
oblique & (2) $y=0.77 x-1.6$ & 0.98 & 3.5 \\
Long axis oblique & (1) $y=0.64 x-0.3$ & 0.91 & 2.2 \\
Hepatoclavicular & (2) $y+0.85 x-1.9$ & 0.99 & 2.6 \\
Sitting up & (1) $y=0.98 x-2.1$ & 0.93 & 2.0 \\
& (2) $y=0.86 x-0.8$ & 0.99 & 2.3 \\
& (1) $y=0.69 x-0.5$ & 0.96 & 1.1 \\
& (2) $y=0.95 x-2.3$ & 0.97 & 4.4 \\
\hline
\end{tabular}

None of the differences between groups 1 and 2 was significant. calculated by the area-length or Simpson's rule $\stackrel{c}{\Rightarrow}$ methods. Previous investigations have shown excellent correlations (correlation coefficient $>0.90$ ) between calculated and cast volumes. ${ }^{7-9}$ In congenital heart disease, however, the left ventricle sometimes $\frac{\rho}{5}$ assumes a prolate shape because of abnormal right $\stackrel{\Phi}{\propto}$ ventricular haemodynamic function. This may affect $\oplus_{\mathscr{N}}$ the accuracy of the area-length method, which $\overrightarrow{ }$ assumes that the left ventricular cavity may be ${ }^{\circ}$ represented as a three-dimensional ellipsoid of $\frac{\vec{\omega}}{\vec{\omega}}$ revolution. ${ }^{111}$ Simpson's rule is usually applied to $\stackrel{\text { S }}{ }$ volume determination of right ventricle because the morphology of this chamber is less complex. ${ }^{12}$ In our 9 study, regression equations for the five projectionsi yielded excellent correlation coefficients $(>0.96) \vec{\infty}$ with small standard errors of estimate $(<3.6 \mathrm{ml})$. N

Comparisons between the groups showed there $\mathrm{O}$ were no statistical differences between regression equations for different projections. These results ${ }_{\mathbb{Q}}^{T}$ suggest that Simpson's rule was not affected when the shape of left ventricle was altered by abnormal right ventricular haemodynamic function. We have previously reported that volumes calculated by the $\vec{\varnothing}$ area-length method overestimated the true volumes. if the haemodynamic function of the right ventricle is abnormal. ${ }^{2}$ The present study suggests that Simpson's rule is more accurate than the area-length method because it is less dependent on the geometry of the ventricle. It seems that the prolate shape of the ${ }_{\Omega}^{\circ}$ left ventricle (banana shaped) in simple transposition $\Rightarrow$ of the great arteries affects the estimation of the minor axis by the length-area approach.

The regression equations for conventional ando non-conventional projections were statistically different in our study. To our knowledge, there are few previous investigations of the use of Simpson's? rule to determine left ventricular volume in these 3 non-conventional projections $s^{1314}$ and no reports of investigations of the hepatoclavicular and sitting up projections. Previous studies of casts made from anatomically normal hearts did not show any? differences in the slopes of regression equation between conventional and long axis oblique views. This may be because earlier studies used casts of ${ }^{N}$ different types or sizes. Our investigation suggests that different regression equations should be used to assess the size of left ventricle by left ventriculo- $\omega$ graphy in non-conventional views.

We conclude that Simpson's rule should be applied to the determination of left ventricular volume in complex congenital heart disease because it is more independent of the shape of the left ventricle. Non-conventional views, however, require different regression equations to calculate left $\frac{\odot}{\mathbb{Q}}$ ventricular volumes.

LNB was supported by a grant from the Research Institute in the Hospital for Sick Children, Toronto 


\section{References}

1 Dodge HT, Sandler H, Ballew DV, Lord JD. The use of biplane angiocardiography for the measurement of left ventricular volume in man. Am Heart $J$ 1960;60:762-76.

2 Ino T, Benson LN, Booty JH, Mikailian H, Rowe RD. Biplane left ventricular volumetry in infants and children. An abnormal cast study [Abstract]. Circulation 1986;74(suppl II):403.

3 Graham TP, Jamakani JM, Atwood GF, Canent R. Right ventricular volume determinations in children. Normal values and observations with volume or pressure overload. Circulation 1973;47:144-53.

4 Graham TP, Jamakani JM, Canent RV, Morrow MN. Left heart volume estimation in infancy and childhood. Reevaluation of methodology and normal values. Circulation 1971;43:895-904.

5 Bargeron LM, Elliott LP, Soto B, Bream PR, Curry GC. Axial cineangiography in congenital heart disease. Section I. Concept, technical and anatomic considerations. Circulation 1977;56:1075-83.

6 Fisher EA, DuBrow IW, Hastreiter AR. Right ventricular volume in congenital heart disease. $\mathrm{Am} \mathrm{J}$ Cardiol 1975;36:67-75.

7 Formanek A, Schey HM, Ekstrand KE, Velasquez G,
D'Souza VJ, Glass TA. Single versus biplane right and left ventricular volumetry: a cast and clinical study. Cathet Cardiovasc Diagn 1984;10:137-56.

8 Arcilla RA, Tsai P, Thilenius O, Banniger K. Angiographic method for volume estimation of right and left ventricles. Chest 1971;60:446-54.

9 Lange PE, Onnasch D, Farr FL, Heintzen PH. Angiocardiographic left ventricular volume determination. Accuracy, as determined from human casts, and clinical application. Eur J Cardiol 1978;8:449-76.

10 Sandler H, Alderman E. Determination of left ventricular size and shape. Circ Res 1974;34:1-8.

11 Gault JH. Angiographic estimation of left ventricular volume. Cathet Cardiovasc Diagn 1975;1:7-16.

12 Shimazaki Y, Kawaskima Y, Mori T, Beppu S, Yokota $K$. Angiographic volume estimation of right ventricle. Reevaluation of previous methods. Chest 1980; 77:390-5.

13 Starling MR, Walsh RA. Accuracy of biplane axial oblique cineangiographic left ventricular cast volume determinations using a modification of Simpson's rule algorithm. Am Heart J 1985;110:1219-25.

14 Pietras RJ, Kondos GT, Juska J. Quantitative validation of cineangiographic axial oblique biplane left ventricular volume measurement. Cathet Cardiovasc Diagn 1987;12:157-61. 